FMCC conference costs. The call for applications occurs in the fall each year. Applications require a Program Director letter of support, the candidate's statement of interest, and completion of the STFM On-line Advocacy Course. The deadline for applications is in December with announcement of winners in January. Selection of resident scholarship winners from across the country is based upon their commitment to legislative advocacy. The selection committee also makes efforts to select a group of winners that represents geographic diversity. Scholarship winners will be invited to attend a function during the conference to meet other awardees and will be required to submit a report afterwards, including a presentation of their experience to their home program.

AFMRD is committed to providing opportunities to teach leadership and advocacy. We hope you will take advantage of this opportunity by encouraging residents to apply. Finally, based on the large pool of enthusiastic applicants we received in the last 2 years, there is a clear need and desire for more resident participation in this conference. The AFMRD encourages programs to not only promote this opportunity, but to consider using local resources to create more scholarships to support resident attendance.

Karen Mitchell, MD, Lisa Maxwell, MD

Brian Crownover, $M D_{i}$ Grant Hoekzema, $M D_{i}$

Nathan Krug, MD, Michael Mazzone, $M D_{i}$

$W$. Fred Miser, $M D_{i}$ Stephen Scbultz, $M D_{i}$

Todd Shaffer, MD, MBA, Michael Tuggy, MD

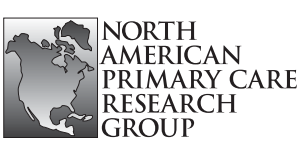

From the North American

Primary Care Research Group

Ann Fam Med 2013;485. doi:10.1370/afm.1577.

\section{NAPCRG CONFERENCE SUMMARIES AVAILABLE}

The NAPCRG website is now a resource for researchers and clinicians looking for summaries of conference sessions and workshops. Many sessions from this year's PBRN Conference and the 2012 Annual Meeting are now available at http://www.napcrg.org.

Find a special web page devoted to the topic of evaluating practice transformation with content from the 2012 Annual Meeting. There are video clips of interviews with presenters and summaries of sessions.

Also, an open forum to discuss evaluating practice transformation is available with the opportunity to comment and share with colleagues. Post new informa- tion, provide your experiences, and share resources with fellow researchers.

Click on the conference web page for the summaries and resources.

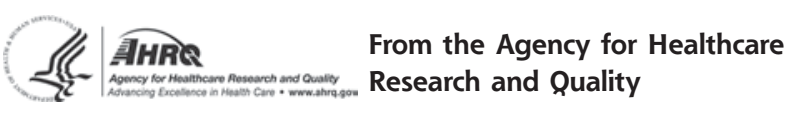

Ann Fam Med 2013;485-486. doi:10.1370/afm.1579.

\section{AHRQ UPDATES ON PRIMARY CARE RESEARCH: MULTIPLE CHRONIC CONDITIONS RESEARCH NETWORK}

Almost one-third of all Americans-and $80 \%$ of older Americans-are estimated to have at least 2 or more concurrent chronic conditions that collectively have an adverse effect on health status, function, or quality of life, and that require complex approaches to health care. ${ }^{1,2}$ Treatment for people living with multiple chronic conditions (MCC) accounts for an estimated $71 \%^{1}$ of the Nation's health care costs, and $93 \%$ of Medicare expenditures. ${ }^{3}$ The number of people with MCC is growing, and is expected to continue to grow as the population ages. However, relatively little is known about how to best treat these patients. Most medical research remains focused on single conditions, and clinical care guidelines rarely address comorbid conditions. Adherence to multiple guidelines that each focus on a single condition is often impractical for patients, and treatment for one condition can have negative effects on other conditions. To make matters worse, clinicians are often compensated based on disease-specific performance measures, which may encourage unnecessary, and even potentially harmful, care for patients with MCC.

The Agency for Healthcare Research and Quality (AHRQ) is working to build the evidence base to support better care for people with MCC in support of the Department of Health and Human Services' national Strategic Framework on Multiple Chronic Conditions. ${ }^{4}$ In particular, AHRQ's Improving Primary Care initiative aims to improve health outcomes and quality of life for people with MCC by improving the quality, safety, efficiency, and effectiveness of evidence-based preventive and chronic care services. As part of this effort, AHRQ funded the Multiple Chronic Conditions Research Network to help advance the field of MCC research, provide needed guidance for clinicians and patients, and advise policymakers about improved methods to measure and promote quality care for patients with complex multiple conditions. In 
addition, AHRQ's Improving Primary Care Initiative currently sponsors a number of initiatives related to improving care for patients with MCC, including work on: care coordination, team-based care, self-management support, clinical decision support, integration of behavioral/mental health with primary care, clinicalcommunity linkages, health information technology integration, and healthcare/system redesign.

The AHRQ MCC Research Network comprises 18 pioneer grant projects funded in 2008, and an additional 27 grant studies funded in 2010 through the American Recovery and Reinvestment Act (ARRA). Each of the 2008-funded studies focused on the use of preventive services for patients with MCC to improve understanding about which interventions provide the greatest benefit to people with MCC. The 2010 funded grants focused on exploratory research or infrastructure development to address comparative effectiveness research to optimize prevention and healthcare management for the complex patient. Roughly one-half of the 2010 funded grants used existing, or easily developed, data sources to help prioritize testing and treatments for patients with MCC, and to suggest appropriate adaptations to recommended care guidelines. The remaining investigators developed new datasets or other infrastructure to fill a void in research on MCC and conducted pilot studies to demonstrate the use of the new infrastructure. They also worked to make these new data sets publically accessible to other researchers. AHRQ also funded a Technical Assistance Center (TAC) to support the work of the MCC Research Network by facilitating information sharing and collaboration across the Network investigators. The TAC is staffed by Abt Associates, the MacColl Center for Healthcare Innovation, and the Inter-University Consortium for Political and Social Research (ICPSR).

\section{Where to Get More Information}

MCC Research Network Results and Products Findings and other materials developed through the AHRQ MCC Research Network are being disseminated through various mechanisms, including the AHRQ MCC Research Network website: http://www. ahrq.gov/research/mccrn.htm.

Access to MCC Research Network Data Several of the datasets developed as a part of this work are publicly available, and are housed on the AHRQ MCC Research Network Data Archive site: http://www.icpsr. umich.edu/icpsrweb/AHRQMCC/.

\section{References}

1. Abt Associates Inc. Unpublished Analysis of 2010 Medical Expenditure Panel Survey (MEPS) Data. Cambridge, MA: Abt Associations; 2013.
2. National Quality Forum. Multiple Chronic Conditions Measurement Framework Final Report. May 2012. http://www.qualityforum.org/ Publications/2012/05/MCC_Measurement_Framework_Final_Report. aspx. Accessed Jun 11, 2013.

3. Centers for Medicare and Medicaid Services. Chronic Conditions among Medicare Beneficiaries, Chartbook, 2012 Edition. Baltimore, MD: Centers for Medicare and Medicaid Services; 2012. http:// www.cms.gov/Research-Statistics-Data-and-Systems/Statistics-Trendsand-Reports/Chronic-Conditions/Downloads/2012Chartbook.pdf. Accessed Jun 11, 2013.

4. US Department of Health and Human Services. Multiple Chronic Conditions-A Strategic Framework: Optimum Health and Quality of Life for Individuals with Multiple Chronic Conditions. Washington, DC; HHS; 2010.

\section{SAFP}

Ann Fam Med 2013;486-487. doi:10.1370/afm.1576.

\section{CMS PROPOSES NEW CODES IN 2014 FEE SCHEDULE TO BENEFIT FAMILY PHYSICIANS}

The AAFP's significant work to urge the Centers for Medicare and Medicaid Services (CMS) to recognize the work involved when family physicians and other primary care professionals take care of patients with chronic conditions is bearing fruit. For example, in the proposed 2014 Medicare physician fee schedule (MPFS), CMS is recommending new codes in 2015 to manage complex chronic care (CCC) conditions, a mainstay of most primary care physicians' practices.

CMS said it is "proposing to establish a separate payment under the MPFS for complex chronic care management services furnished to patients with multiple complex chronic conditions that are expected to last at least 12 months or until the death of the patient, and that place the patient at significant risk of death, acute exacerbation/decompensation or functional decline."

A recent AAFP summary of the proposed MPFS, available at http://www.aafp.org/dam/AAFP/documents/ advocacy/payment/medicare/ES-2014ProposedFeeSchedule-071913.pdf notes that these new codes represent a step toward a more equitable payment system that would better recognize and reward the provision of primary care physician services.

CMS is proposing 2 new G-codes: one for the initial service and another for subsequent care after the initial service. The agency would pay only $1 \mathrm{G}$-code per patient during a 90 -day period. CMS has not yet determined the payment amount, but, according to the 